\title{
Safety and immunogenicity of a fully liquid vaccine containing five-component pertussis-diphtheria- tetanus-inactivated poliomyelitis-Haemophilus influenzae type b conjugate vaccines administered at two, four, six and 18 months of age
}

\author{
Ronald Gold MD MPH ${ }^{1}$, Luis Barreto $M B B S M D M H S^{2}$, Santiago Ferro $\mathrm{MD}^{2}$, John Thippawong $\mathrm{MD}^{2}$, \\ Roland Guasparini $\mathrm{MD}^{3}$, William Meekison $\mathrm{MD}^{4}$, Margaret Russell $\mathrm{MD}^{5}$, Elaine Mills $\mathrm{MD}^{2}$, \\ Dana Harrison BA MA², Pierre Lavigne $\mathrm{MD}^{2}$
}

R Gold, L Barreto, S Ferro, et al. Safety and immunogenicity of a fully liquid vaccine containing five-component pertussisdiphtheria-tetanus-inactivated poliomyelitis-Haemophilus influenzae type $\mathrm{b}$ conjugate vaccines administered at two, four, six and 18 months of age. Can J Infect Dis Med Microbiol $2007 ; 18(4): 241-248$.

OBJECTIVE: The safety, immunogenicity and lot consistency of a fully liquid, five-component acellular pertussis combination vaccine, comprised of diphteria, tetanus and acellular pertussis, inactivated polio vaccine, Haemophilus influenzae type b (DTaP-IPV-Hib [Pediacel, sanofi pasteur, Canada]) were assessed and compared with that of Hib vaccine reconstituted with the five-component acellular pertussis combination vaccine (DTaP-IPV//Hib, Pentacel [sanofi pasteur, Canada]).

METHODS: Infants were recruited at vaccine study centres in Montreal, Quebec; Simon Fraser Health Region, British Columbia, and southern Alberta after the protocol had been approved by the relevant institutional ethics committees. Written informed consent was obtained from the parents or guardians of all subjects. At two months of age, the infants were randomly assigned to receive one of three consecutive production lots of DTaP-IPV-Hib by intramuscular injection. Reactions to vaccinations were assessed by parental observation and through telephone interviews conducted by study nurses. Blood samples were obtained at two, six, seven, 18 and 19 months of age for measurement of antibodies to vaccine antigens.

RESULTS: Most injection site and systemic reactions were mild or moderate, and of brief duration. All infants were protected against tetanus, diphtheria and all three polio serotypes after both primary and booster vaccinations. Antibody responses to pertussis antigens were similar to those observed in Swedish infants, in whom the fivecomponent vaccine was shown to be $85 \%$ effective. Proportions of infants with antipolyribosylribitol phosphate antibody of $0.15 \mu \mathrm{g} / \mathrm{mL}$ or greater and $1.0 \mu \mathrm{g} / \mathrm{mL}$ or greater, were $97.9 \%$ and $88.9 \%$, respectively, following primary immunization, and $100 \%$ and $99 \%$ following booster vaccination. Safety and immunogenicity results with both reconstituted and fully liquid combination vaccines were comparable.

CONCLUSIONS: The fully liquid combination vaccine was comparable in terms of safety and immunogenicity with the reconstituted combination vaccine.

Key Words: Acellular pertussis vaccine; Combination vaccine; Diphtheria toxoid; Haemophilus influenzae type b conjugate vaccine; Inactivated polio vaccine; Tetanus toxoid
L'innocuité et l'immunogénicité d'un vaccin entièrement liquide contenant les cinq éléments (diphtérie, tétanos, coqueluche, poliomyélite inactivée et Haemophilus influenzae de type $b$ ) des vaccins conjugués administrés à deux, quatre, six et 18 mois

OBJECTIF : On a évalué et comparé l'innocuité, l'immunogénicité et l'homogénéité des lots d'un vaccin anticoquelucheux entièrement liquide combiné à cinq éléments comportant les anatoxines diphtérique et tétanique, le vaccin antipoliomyélitique inactivé et le vaccin conjugué contre l'Haemophilus influenzae de type b (DTCa-VPI-Hib [Pediacel, sanofi pasteur, Canada]) avec ceux d'un vaccin contre le Hib reconstitué avec le vaccin anticoquelucheux combiné à cinq éléments (DTCa-VPI//Hib, [Pentacel, sanofi pasteur, Canada]).

MÉTHODOLOGIE : Les nourrissons ont été recrutés dans des centres d'études des vaccins de Montréal, au Québec, de la région sanitaire de Simon Fraser, en Colombie-Britannique, et du sud de l'Alberta après l'approbation du protocole par les comités d'éthique pertinents de chaque établissement. On a obtenu le consentement éclairé écrit de la part des parents ou des tuteurs de tous les sujets. À l'âge de deux mois, les nourrissons ont été divisés au hasard pour recevoir l'un des trois lots consécutifs de fabrication du DTCa-VPI-Hib par injection intramusculaire. Les réactions aux vaccins ont été évaluées d'après les observations des parents et des entrevues téléphoniques effectuées par les infirmières responsables du projet. On a prélevé des analyses sanguines à deux, six, sept, 18 et 19 mois pour mesurer les anticorps aux antigènes du vaccin.

RÉSULTATS : La plupart des réactions systémiques ou au foyer d'injection étaient bénignes ou modérées et de courte durée. Tous les nourrissons étaient protégés contre le tétanos, la diphtérie et les trois sérotypes de la polio après le vaccin primaire et la dose de rappel. Les réponses des anticorps aux antigènes de la coqueluche étaient similaires à celles observées chez des nourrissons suédois, pour qui le vaccin à cinq éléments était efficace à $85 \%$. Les proportions de nourrissons possédant de $0,15 \mu \mathrm{g} / \mathrm{mL}$ ou plus et de $1,0 \mu \mathrm{g} / \mathrm{mL}$ ou plus d'anticorps au phosphate antipolyribosylribitol étaient de $97,9 \%$ et de $88,9 \%$, respectivement, après l'immunisation primaire, et de $100 \%$ et $99 \%$ après la dose de rappel. Les résultats d'innocuité et d'immunogénicité avec le vaccin combiné reconstitué et le vaccin combiné entièrement liquide étaient comparables. CONCLUSIONS : Le vaccin combiné entièrement liquide était comparable au vaccin combiné reconstitué en matière d'innocuité et d'immunogénicité.

\footnotetext{
${ }^{1}$ The Hospital for Sick Children; ${ }^{2}$ sanofi pasteur Ltd, Toronto, Ontario; ${ }^{3}$ Boundary Health Unit, Surrey; ${ }^{4}$ Simon Fraser Health Region, Coquitlam, British Columbia; ${ }^{5}$ Department of Community Health Sciences, University of Calgary, Calgary, Alberta

Correspondence and reprints: Dr Luis Barreto, 1755 Steeles Avenue West, North York, Ontario M2R 3T4. Telephone 416-667-2738,

fax 416-667-2865, e-mail Luis.Barreto@sanofipasteur.com

Received and accepted for publication June 4, 2007
} 
$\mathrm{D}_{\mathrm{h}}^{\mathrm{i}}$ phtheria, tetanus and acellular pertussis (DTaP) vaccines have been shown to be safe, immunogenic and effective in preventing pertussis in infants $(1-25)$. DTaP vaccines have been licensed and incorporated into routine immunization of infants in Canada, the United States and most countries in Europe.

There are large variations in the antigenic compositions (range of one to five antigens) of different acellular pertussis vaccines. There is no serological correlate of protection for pertussis, but clinical studies and extensive field experience have shown all licensed DTaP vaccines to be safe, immunogenic and effective in preventing pertussis in infants when high levels of vaccination coverage are achieved. The fivecomponent pertussis vaccine containing pertussis toxoid (PT), filamentous hemagglutinin (FHA), pertactin (PRN) and fimbriae (FIM) 2 and 3, developed by sanofi pasteur (Canada) and administered together with diphtheria and tetanus toxoids, was shown to be $85 \%$ effective in preventing severe pertussis (minimum of 21 days of paroxysmal cough), and $78 \%$ effective in preventing clinical illness regardless of severity, including mild illness (at least one day of cough) $(20,21)$. Two DTaP, inactivated polio vaccine, Haemophilus influenzae type $b$ (DTaP-IPV-Hib) combinations have been developed by sanofi pasteur (Canada) based on this acellular pertussis vaccine; one of these combinations (DTaP-IPV//Hib [Pentacel]) in which lyophilized Hib tetanus toxoid conjugate is reconstituted with liquid DTaP-IPV (Quadracel, sanofi pasteur) has been used exclusively in Canada since 1998 (26,27). Antibody responses against pertussis antigens with this vaccine were similar to those observed with DTaP in the Swedish field trials $(20,21,28,29)$. Since its introduction as a replacement for whole-cell pertussis vaccine (ie, diphtheria, tetanus and whole-cell pertussis [DTwP]) in Canada between 1997 and 1998, the reported incidence of pertussis in infants and preschool children, and rates of vaccine-related adverse events both decreased (30,31). Longer-term postmarketing experience, with over 10 million doses used to date, has demonstrated the high effectiveness of DTaP-IPV//Hib, particularly against pertussis and Hib diseases $(30,32)$.

The second pentavalent DTaP-IPV-Hib vaccine (Pediacel, sanofi pasteur), developed by sanofi pasteur as a fully liquid product to eliminate the need to reconstitute the lyophilized Hib vaccine before use, was first licensed in 2000 in Canada. This combination vaccine contains the same DTaP components as reconstituted DTaP-IPV//Hib, but the IPV component is produced using Vero cells rather than MRC-5 cells, and the Hib conjugate vaccine is included in the fully liquid preparation. When countries such as England and Wales switched from DTwP and oral poliovirus vaccines (OPVs) to acellular pertussis and IPVs in September 2004, the fully liquid DTaPIPV-Hib vaccine was selected (33). This vaccine was chosen because the five-component acellular pertussis proved its clinical efficacy against both typical and mild pertussis disease and displayed little or no interference against the included Hib component, unlike other acellular pertussis vaccines (34-37).

The present study reports on the safety, tolerability and immunogenicity of the fully liquid DTaP-IPV-Hib vaccine when administered in the complete four-dose Canadian series at two, four, six and 18 months of age, assessed through the lot-to-lot consistency study for licensure. The study was part of a larger clinical program carried out between 1995 and 1998, with different formulations of DTaP-IPV and polyribosylribitol phosphate conjugated to tetanus toxoid (PRP-T) vaccines.
Results with one such formulation, the reconstituted DTPIPV//PRP-T, were published (27) because of the decision at that time to distribute the reconstituted combination vaccine in Canada. In view of the use of the fully liquid DTaP-IPV-Hib combination vaccine in England, Wales and in Europe, and plans to distribute it in Canada, the results of the lot consistency of this vaccine in line with current guidance on the disclosure of licensed products is now reported.

\section{METHODS}

\section{Study design}

The present randomized controlled trial was carried out between 1995 and 1998. Subjects were recruited at vaccine study centres in Montreal, Quebec; Simon Fraser Health Region, British Columbia, and southern Alberta. The study protocol was approved by the relevant institutional ethics committees and was conducted in accordance with the Declaration of Helsinki good clinical practice and applicable International Conference on Harmonization guidelines. Witnessed, written informed consent was obtained from the parents or guardians of all subjects before enrolment.

During their first visit at two months of age, the infants were randomly assigned in equal numbers to receive one of three consecutive production lots of DTaP-IPV-Hib. The vaccine was administered by intramuscular injection into the anterolateral thigh at two, four, and six months of age and into the deltoid muscle at 18 months of age. Parent(s) or guardian(s) were blinded as to which vaccine lot their children had received.

Inclusion criteria required that infants be two to three months of age (not yet reached four months of age) and in generally good health, and the family intended to remain in the study area for a minimum of six months from the time of enrolment. Exclusion criteria were: known or suspected disease of the immune system; malignancy; receiving immunosuppressive therapy; a major congenital malformation or condition; serious chronic illness; history of developmental delay or neurological disorder including seizures, history of clinical or laboratory confirmed pertussis; prior receipt of DTP, Hib or polio vaccines or immune globulin; and known or suspected allergy to any of the vaccine components.

\section{Vaccine}

Each $0.5 \mathrm{~mL}$ dose of the fully liquid DTaP-IPV-Hib contained $15 \mathrm{Lf}$ of diphtheria toxoid, $5 \mathrm{Lf}$ of tetanus toxoid, $20 \mu \mathrm{g}$ of PT, $20 \mu \mathrm{g}$ of FHA, $3 \mu \mathrm{g}$ of PRN, $5 \mu \mathrm{g}$ of FIM 2 and 3, $40 \mathrm{D}$ of antigen units poliovirus type $1,8 \mathrm{D}$ of antigen units poliovirus type 2, $32 \mathrm{D}$ of antigen units poliovirus type 3 (Vero cell) and $10 \mu \mathrm{g}$ of purified polyribosylribitol phosphate capsular polysaccharide of Hib covalently bound to $20 \mu \mathrm{g}$ of tetanus toxoid (PRP-T), with $0.6 \%$ of 2-phenoxyethanol and $1.5 \mathrm{mg}$ of aluminum phosphate. Three consecutive production lots were used (A5I-85000-11, A5I-85001-11 and A5I-85002-11).

\section{Safety}

All infants were monitored for 30 min after each injection for any immediate reactions. Parents or guardians of study participants recorded any reactions on diary cards within the $72 \mathrm{~h}$ following each immunization, which solicited for injection site redness, swelling and tenderness, and for fever, fussiness, irritability, altered appetite, drowsiness, vomiting and diarrhea. The extent of injection site redness and swelling were measured with a clear celluloid template, printed with concentric circles of $5 \mathrm{~mm}$ to $50 \mathrm{~mm}$ in diameter. Severe injection site 
reactions were defined as crying when the limb was moved, indicating severe tenderness, and redness or swelling with a circumference of $35 \mathrm{~mm}$ or greater. Parents or guardians received digital thermometers to record their child's axillary or rectal temperature at defined times after each immunization. Fever was defined as a temperature of $38^{\circ} \mathrm{C}$ or higher. At the time of the study, fever prophylaxis with acetaminophen was recommended routinely at all centres except at the Montreal centre, in which parents were advised to use acetaminophen only if they deemed it was necessary (38).

When present, solicited systemic reactions were graded as mild, moderate or severe. Approximately $24 \mathrm{~h}$ and $72 \mathrm{~h}$ after each vaccination, parents or guardians were contacted by telephone to complete questionnaires assessing the participant's local and systemic reactogenicity during the first $24 \mathrm{~h}$, and $24 \mathrm{~h}$ to $72 \mathrm{~h}$ postimmunization, respectively. At each study visit, parents or guardians were questioned concerning events that had occurred at any time after the previous immunization; unsolicited adverse events observed by parents up to 35 days following doses 3 and 4 were recorded. Study nurses were authorized to visit children at home if unsolicited adverse events or solicited reactions were severe. They followed the children until the problems had resolved.

\section{Serology}

Blood samples were obtained at two months of age (before dose 1), six months of age (before dose 3), 28 to 35 days after dose 3 , at 18 months of age (before dose 4) and 28 to 35 days after dose 4. Sera were separated immediately and maintained at $-20^{\circ} \mathrm{C}$ during storage and transport to sanofi pasteur for antibody determinations. Antibodies were measured by ELISA for PT, FHA, PRN, FIM and tetanus, by microneutralization for diphtheria, by neutralization for poliovirus types 1, 2 and 3, and by Farr-type radioimmunoassay for Hib anti-PRP antibodies $(5,6,39)$.

\section{Sample size}

The sample size of 100 children per vaccine group was estimated to have $63 \%$ and $97 \%$ power to detect a $10 \%$ or $20 \%$ reduction in the proportion of subjects achieving anti-PRP antibody concentrations of $1.0 \mu \mathrm{g} / \mathrm{mL}$ or greater, respectively, and $87 \%$ power to detect a $10 \%$ reduction in the fourfold response rate to IPV; $10 \%$ was added to each vaccine group to account for dropouts. This sample size of 100 children per vaccine group was not large enough to conduct between-group comparisons in rates of injection site and systemic reactions between lots of DTaP-IPV-Hib.

\section{Statistical analysis}

Data were analyzed using SAS for Windows software (Microsoft Corporation, USA). The rates and severities of solicited injection site and systemic reactions were calculated for the $72 \mathrm{~h}$ period following immunization. Because there were no clinically relevant differences in rates of reactions among lots, the results for the three lots were pooled and reported descriptively.

Geometric mean concentrations (GMCs) or geometric mean titres (GMTs) for antibodies with 95\% CI were calculated for each antigen contained in the combination vaccine. Seroprotection rates were defined as an anti-PRP level of $0.15 \mu \mathrm{g} / \mathrm{mL}$ or greater and $1.0 \mu \mathrm{g} / \mathrm{mL}$ or greater, for shortand long-term protection, respectively; neutralizing antibody titres of eight or greater for polio types 1, 2 and 3; diphtheria antitoxin levels of $0.01 \mathrm{IU} / \mathrm{mL}$ or greater, and tetanus antitoxin levels of $0.01 \mathrm{EU} / \mathrm{mL}$ or greater. Fourfold responses to each pertussis antigen were determined by calculating the ratio of the antibody concentrations at seven months to that at two months of age and the ratio at 19 months to 18 months of age. Seroconversion rates were calculated on the basis of the following definitions:

1. Seroconversion at seven months of age - antibody response at or greater than the lower limit of quantitation (LLOQ) in subjects whose antibody concentration at two months of age was less than the LLOQ or whose antibody response was greater than the concentration observed at two months of age if the concentration at two months of age was greater than the LLOQ.

2. Seroconversion at 19 months of age - fourfold rise in antibody if the concentration at 18 months of age was less than four times the LLOQ or a twofold rise in antibody if the concentration at 18 months of age was greater than four times the LLOQ.

Because there were no significant differences in antibody responses among lots (with one exception described in the Immunogenicity section of Results), the antibody results for the three lots have been pooled in the present report.

In the full clinical program, which also included the reconstituted DTaP-IPV//PRP-T and DTwP-IPV//PRP-T, surveillance for adverse events following immunization was the same for all vaccine groups and serum antibody responses were measured in the same laboratory. Therefore, it is appropriate to compare the results for the fully liquid vaccine with those previously published for the reconstituted acellular pertussis vaccine (27). The publication only reported results for the primary immunization series at two, four and six months of age, and adverse events were reported separately for $0 \mathrm{~h}$ to $24 \mathrm{~h}$ and $24 \mathrm{~h}$ to $72 \mathrm{~h}$ periods. These rates have been recalculated for the $\mathrm{O} \mathrm{h}$ to $72 \mathrm{~h}$ period to allow direct comparison with the results for the fully liquid DTaP-IPV-PRP-T. The previously unpublished safety and immunogenicity results for the booster given at 18 months of age have also been included. Proportions of subjects receiving acetaminophen prophylaxis at the time of immunization were similar in all vaccine groups.

\section{RESULTS}

\section{Enrolment, withdrawals and exclusions}

Of the 339 infants enrolled at the three study centres (166 at the Montreal centre, 116 at Simon Fraser Health Region and 57 at the southern Alberta centre), 330 (97.3\%) received the first three doses of vaccine. Nine subjects were lost to follow-up before the third dose at six months of age and two more subjects were lost between dose 3 and blood sampling at seven months of age. The reasons for the losses were serious adverse event (one child with two afebrile seizures; see details below), parental request (four children), lost to follow-up (three children), moved out of the study region (one child) and other reasons (two children).

Of the 330 infants who completed the first three doses, blood samples were available from 324 infants at seven months of age. At the time of the booster at 18 months of age, blood samples from 301 infants were available.

There were no differences in the age distributions or sex ratios among vaccine groups at the primary series or at the booster stage. Overall, 53.4\% of the subjects were male. 
TABLE 1

Percentages of infants with injection site reactions in the $72 \mathrm{~h}$ after immunization with fully liquid DTaP-IPV-Hib vaccine at two, four, six and 18 months of age, presented with historical data on reconstituted DTaP-IPV//Hib vaccine for comparison

\begin{tabular}{lccc}
\hline & & \multicolumn{2}{c}{$\begin{array}{c}\text { Any injection site reaction } \\
\text { after indicated vaccine (\%) }\end{array}$} \\
\cline { 3 - 4 } Injection site reaction & Age (months) & DTaP-IPV-Hib & DTaP-IPV//Hib \\
\hline Redness, any & 2 & 2.7 & 4.5 \\
& 4 & 6.0 & 5.8 \\
Swelling, any & 6 & 4.5 & 6.2 \\
& 18 & 18.3 & 18.4 \\
& 2 & 10.7 & 10.4 \\
Tenderness, any & 4 & 8.7 & 6.7 \\
& 6 & 7.0 & 6.2 \\
& 18 & 11.3 & 13.0 \\
& 2 & 23.1 & 26.6 \\
& 4 & 21.9 & 27.4 \\
& 6 & 14.8 & 19.9 \\
& 18 & 35.5 & 29.1
\end{tabular}

*The number of subjects evaluated after doses 1 to 4 , respectively, were: diphtheria, tetanus and acellular pertussis, inactivated polio vaccine and Haemophilus influenzae type b (DTaP-IPV-Hib) - 338, 333, 330 and 301, and DTaP-IPVI/Hib - 335, 329, 323 and 299; 'Data on file (sanofi pasteur, Canada)

Safety

Injection site adverse events: The rates of injection site redness, swelling and tenderness within the $72 \mathrm{~h}$ following each immunization are summarized in Table 1 . Most injection site reactions occurred within $24 \mathrm{~h}$ of vaccination, and nearly all those classified as severe occurred within this period, with very few reports of severe symptoms after $24 \mathrm{~h}$ (data not shown). The most common injection site reaction was tenderness, reported within $72 \mathrm{~h}$ after $23.1 \%, 21.9 \%$ and $14.8 \%$ of doses 1, 2 and 3, respectively. Tenderness graded as severe occurred in $0.6 \%$ to $2.4 \%$ of cases. Reports of redness $(2.7 \%$ to $6.0 \%)$ and swelling (7\% to $10.7 \%)$ in the $72 \mathrm{~h}$ after the first three doses were less frequent than tenderness. Severe injection site redness and swelling were reported after $1.2 \%$ and $5.1 \%$ of doses, respectively. Local tenderness was less frequent after the third dose compared with the first dose, but there was no consistent trend toward increasing or decreasing reactions after each of the first three consecutive doses.

Injection site redness, swelling and tenderness were reported more frequently after the booster at 18 months of age than with the primary series (Table 1 ). However, the change in site of injection from the thigh (for the primary series) to the deltoid muscle (for the booster) may have affected the frequency and extent of local adverse reactions, making it difficult to interpret any differences in the observed rates (40). Although extensive swelling of the whole limb was not a solicited reaction, none was reported by parents after primary or booster vaccinations.

Systemic adverse events

The most frequent solicited systemic reaction reported within $72 \mathrm{~h}$ of vaccination was increased fussiness, which occurred after $48.2 \%$ to $56.8 \%$ of the first three vaccine doses (Table 2). This was frequently accompanied by reports of crying (30.9\% to $45.3 \%)$. Fever $\left(38^{\circ} \mathrm{C}\right.$ or higher) was reported in $15.1 \%, 25.8 \%$
TABLE 2

Percentages of infants with solicited systemic reactions in the $72 \mathrm{~h}$ after immunization with fully liquid DTaP-IPV-Hib vaccine at two, four, six, and 18 months of age, presented with historical data with reconstituted DTaP-IPVI/Hib vaccine for comparison

\begin{tabular}{|c|c|c|c|}
\hline \multirow[b]{2}{*}{ Systemic reaction } & \multirow[b]{2}{*}{ Age (months) } & \multicolumn{2}{|c|}{$\begin{array}{l}\text { Any systemic reaction after } \\
\text { indicated vaccine }(\%)^{*}\end{array}$} \\
\hline & & DTaP-IPV-Hib & DTaP-IPV//Hib ${ }^{\dagger}$ \\
\hline \multirow{4}{*}{ Fever $\left(38.0^{\circ} \mathrm{C}\right.$ or higher $)$} & 2 & 15.1 & 25.7 \\
\hline & 4 & 25.8 & 27.0 \\
\hline & 6 & 23.5 & 20.2 \\
\hline & 18 & 32.8 & 32.1 \\
\hline \multirow[t]{4}{*}{ Fussiness } & 2 & 56.1 & 54.3 \\
\hline & 4 & 56.8 & 62.9 \\
\hline & 6 & 48.2 & 45.3 \\
\hline & 18 & 37.2 & 40.5 \\
\hline \multirow[t]{4}{*}{ Crying } & 2 & 39.2 & 40.9 \\
\hline & 4 & 45.3 & 50.2 \\
\hline & 6 & 30.9 & 35.1 \\
\hline & 18 & 25.9 & 28.4 \\
\hline \multirow[t]{4}{*}{ Less active } & 2 & 49.6 & 52.2 \\
\hline & 4 & 34.2 & 34.3 \\
\hline & 6 & 17.9 & 22.7 \\
\hline & 18 & 15.3 & 13.4 \\
\hline \multirow[t]{4}{*}{ Decreased eating } & 2 & 37.1 & 36.7 \\
\hline & 4 & 27.9 & 28.3 \\
\hline & 6 & 23.6 & 25.5 \\
\hline & 18 & 21.9 & 25.1 \\
\hline \multirow[t]{4}{*}{ Vomiting } & 2 & 12.2 & 13.7 \\
\hline & 4 & 9.0 & 8.5 \\
\hline & 6 & 7.0 & 9.6 \\
\hline & 18 & 7.6 & 8.7 \\
\hline \multirow[t]{4}{*}{ Diarrhea } & 2 & 20.2 & 16.4 \\
\hline & 4 & 10.2 & 12.5 \\
\hline & 6 & 13.0 & 13.7 \\
\hline & 18 & 12.3 & 11.0 \\
\hline
\end{tabular}

*The number of subjects evaluated after doses 1 to 4, respectively, were: diphtheria, tetanus and acellular pertussis, inactivated polio vaccine and Haemophilus influenzae type $b$ (DTaP-IPV-Hib) - 338, 333, 330 and 301, and DTaP-IPV//IHib - 335, 329, 323 and 299; 'Data on file (sanofi pasteur, Canada)

and $23.5 \%$ of infants after doses 1,2 and 3 , respectively, but there were no reports of severe fever $\left(40^{\circ} \mathrm{C}\right.$ or higher). Systemic reactions other than fever $(32.8 \%)$ were generally less frequent after the booster at 18 months of age than after the primary series. Nearly all systemic reactions resolved within two to three days, and all resolved without sequelae. Severe systemic reactions were very uncommon after either the primary or booster immunization. The frequency of fever and other systemic reactions tended to decrease with successive doses of vaccine.

Serious adverse events

Only one unsolicited serious adverse event was observed in the present study: a child developed an afebrile seizure lasting $5 \mathrm{~min}$, $24 \mathrm{~h}$ after the third dose of lot 85002-11. A second brief seizure occurred a few hours after the first and a third seizure occured 28 days later. Neurological evaluation during hospitalization was normal. The child remained seizure free on phenobarbital therapy at the time of follow-up one year later. 
TABLE 3

Antibody responses to diphtheria, tetanus toxoid and poliovirus types 1,2 , and 3 after primary series and before and after booster immunization of infants with fully liquid DTaP-IPV-Hib vaccine

\begin{tabular}{|c|c|c|c|c|}
\hline \multirow[b]{2}{*}{ Antigen } & \multirow[b]{2}{*}{ Result } & \multicolumn{3}{|c|}{ Antibody responses at indicated age } \\
\hline & & $\begin{array}{c}7 \text { months } \\
(n=324)\end{array}$ & $\begin{array}{c}18 \text { months } \\
(n=301)\end{array}$ & $\begin{array}{c}19 \text { months } \\
(n=301)\end{array}$ \\
\hline \multirow[t]{4}{*}{ Diphtheria } & GMC, IU/mL & 0.29 & 0.05 & 4.13 \\
\hline & $95 \% \mathrm{Cl}$ & $0.22-0.38$ & $0.04-0.06$ & $3.58-4.76$ \\
\hline & $\% \geq 0.01 \mathrm{IU} / \mathrm{mL}$ & 100 & 92.0 & 100 \\
\hline & $\% \geq 0.10 \mathrm{IU} / \mathrm{mL}$ & 78.7 & 27.2 & 100 \\
\hline \multirow[t]{4}{*}{ Tetanus* } & $\mathrm{GMC}, \mathrm{EU} / \mathrm{mL}$ & 2.86 & 0.53 & 10.1 \\
\hline & $95 \% \mathrm{Cl}$ & $2.62-3.14$ & $0.48-0.59$ & $9.33-11.0$ \\
\hline & $\% \geq 0.01 \mathrm{EU} / \mathrm{mL}$ & 100 & 99.3 & 100 \\
\hline & $\% \geq 0.10 \mathrm{EU} / \mathrm{mL}$ & 99.7 & 96.7 & 100 \\
\hline \multirow[t]{3}{*}{ Polio type 1} & GMT, titre ${ }^{-1}$ & 713 & 110 & 8025 \\
\hline & $95 \% \mathrm{Cl}$ & $526-723$ & $97-137$ & $6649-9160$ \\
\hline & $\%$ titre $^{-1} \geq 8$ & 100 & 94.1 & 100 \\
\hline \multirow[t]{3}{*}{ Polio type 2} & GMT, titre ${ }^{-1}$ & 2520 & 306 & 19,451 \\
\hline & $95 \% \mathrm{Cl}$ & $2026-2800$ & $256-377$ & $15,052-20,486$ \\
\hline & $\%$ titre $^{-1} \geq 8$ & 100 & 99.0 & 100 \\
\hline \multirow[t]{3}{*}{ Polio type 3} & GMT, titre ${ }^{-1}$ & 1458 & 143 & 13,613 \\
\hline & $95 \% \mathrm{Cl}$ & $1079-1485$ & $115-172$ & $10,305-14,962$ \\
\hline & $\%$ titre $^{-1} \geq 8$ & 100 & 94.2 & 100 \\
\hline
\end{tabular}

*Tetanus antitoxin values standardized for change in ELISA assay between seven and 18 months by multiplying seven-month values by 2.62 . DTaP-IPV-Hib Diphtheria, tetanus and acellular pertussis, inactivated polio vaccine and Haemophilus influenzae type b; GMC Geometric mean antibody concentration; GMT Geometric mean antibody titre

\section{Immunogenicity}

There were no statistically significant differences among the three lots of DTaP-IPV-Hib combination vaccine in immune responses (seroprotection, seroconversion or vaccine response rates) to any of the vaccine antigens with the exception of one production lot having a significantly higher anti-FHA GMC (182.4 EU/mL) compared with the other two lots $(128.2 \mathrm{EU} / \mathrm{mL}$ and $159.8 \mathrm{EU} / \mathrm{mL}, \mathrm{P} \leq 0.05)$. Pooled data for all three lots are presented.

Diphtheria, tetanus and polio

Responses to the diphtheria, tetanus and poliovirus components are summarized in Table 3. All subjects had protective titres $(0.01 \mathrm{IU} / \mathrm{mL}$ or greater) against diphtheria and tetanus one month after the third dose of DTaP-IPV-Hib. There was evidence of antibody levels waning from seven to 18 months, but $92 \%$ of subjects still had seroprotective levels to diphtheria, and over $99.3 \%$ against tetanus, before the booster dose. The booster dose elicited marked increases over 14- and 3.5-fold higher than the primary responses for diphtheria and tetanus, respectively, and restored $100 \%$ seroprotection against both toxoids. Indeed, all subjects had the more conservative protective thresholds of $0.1 \mathrm{IU} / \mathrm{mL}$ or greater to diphtheria antitoxin and $0.1 \mathrm{EU} / \mathrm{mL}$ or greater to tetanus antitoxin following the booster dose.

Large responses against all three poliovirus types were observed with the Vero cell-derived IPV. A fourfold increase in antibody titre was observed in $97 \%$ to $99 \%$ of the subjects for the three poliovirus types, and antibody titres of eight or greater for each of the three serotypes were obtained in
TABLE 4

Antibody responses to pertussis antigens after primary series and before and after booster immunization of infants with fully liquid DTaP-IPV-Hib vaccine

\begin{tabular}{|c|c|c|c|c|}
\hline \multirow[b]{2}{*}{ Antigen } & \multirow[b]{2}{*}{ Result } & \multicolumn{3}{|c|}{ Antibody responses at indicated age } \\
\hline & & $\begin{array}{c}7 \text { months } \\
(n=324)\end{array}$ & $\begin{array}{c}18 \text { months } \\
(n=301)\end{array}$ & $\begin{array}{c}19 \text { months } \\
(n=301)\end{array}$ \\
\hline \multirow[t]{4}{*}{ PT } & $\mathrm{GMC}, \mathrm{EU} / \mathrm{mL}$ & 86.7 & 11.9 & 221.7 \\
\hline & $95 \% \mathrm{Cl}$ & $80.8-93.0$ & $10.8-13.8$ & 204-241 \\
\hline & $\%$ fourfold rise* & 92.5 & - & 98.6 \\
\hline & $\%$ seroconversion $^{\dagger}$ & 97.7 & - & 99.7 \\
\hline \multirow[t]{4}{*}{ FHA } & $\mathrm{GMC}, \mathrm{EU} / \mathrm{mL}$ & 155.0 & 19.9 & 265.9 \\
\hline & $95 \% \mathrm{Cl}$ & $146.5-164.1$ & $18.1-21.9$ & $248-285$ \\
\hline & $\%$ fourfold rise* & 86.0 & - & 93.8 \\
\hline & $\%$ seroconversion ${ }^{\dagger}$ & 99.0 & - & 99.0 \\
\hline \multirow[t]{4}{*}{ PRN } & $\mathrm{GMC}, \mathrm{EU} / \mathrm{mL}$ & 55.4 & 9.3 & 207.7 \\
\hline & $95 \% \mathrm{Cl}$ & $48.8-62.8$ & $8.2-10.6$ & $184-235$ \\
\hline & $\%$ fourfold rise* & 85.5 & - & 98.3 \\
\hline & $\%$ seroconversion ${ }^{\dagger}$ & 94.7 & - & 99.7 \\
\hline \multirow{4}{*}{$\begin{array}{l}\text { FIM } 2 \\
\text { and } 3\end{array}$} & $\mathrm{GMC}, \mathrm{EU} / \mathrm{mL}$ & 277.2 & 38.4 & 841.7 \\
\hline & $95 \% \mathrm{Cl}$ & $242.7-316.5$ & $33.4-44.3$ & $748-948$ \\
\hline & $\%$ fourfold rise* & 85.4 & - & 94.1 \\
\hline & $\%$ seroconversion ${ }^{\dagger}$ & 93.7 & - & 99.7 \\
\hline
\end{tabular}

*Fourfold rise: the ratio of the antibody concentrations at seven months to that at two months of age or the ratio at 19 months to 18 months of age was four or greater. 'Seroconversion at seven months of age: antibody response at or greater than the lower limit of quantitation (LLOQ) in subjects whose antibody concentration at two months was less than the $L L O Q$ or antibody response greater than concentration observed at two months of age if concentration at two months was greater than the LLOQ; Seroconversion at 19 months of age: fourfold rise in antibody if concentration at 18 months was less than four times the $L L O Q$ or twofold rise in antibody if concentration at 18 months was greater than four times the LLOQ. DTaP-IPV-Hib Diphtheria, tetanus and acellular pertussis, inactivated polio vaccine and Haemophilus influenzae type b; FHA Filamentous hemagglutinin; FIM Fimbriae; GMC Geometric mean antibody concentration; PRN Pertactin; PT Pertussis toxoid

$100 \%$ of the subjects following both primary and booster vaccinations.

\section{Pertussis}

Strong serological responses to all five pertussis antigens were observed (Table 4). Fourfold increases in antibody concentrations to individual antigen components of the acellular pertussis vaccines were observed in $85.4 \%$ to $92.5 \%$ of the infants and seroconversion rates were $93.7 \%$ to $99.0 \%$ after the primary series depending on the antigen (Table 4). GMCs of antibodies to PT, FHA, PRN and FIM declined between seven and 18 months of age by sixfold to 7.8-fold. Following the booster, anamnestic responses were observed to all pertussis antigens, with seroconversion rates being lower than $99 \%$ and fourfold responses between $93.8 \%$ and $98.6 \%$.

\section{Hib}

Antibody responses to the PRP-T component of the fully liquid DTaP-IPV-Hib vaccine are shown in Table 5. One month after the third dose, the seroprotection rate $(0.15 \mu \mathrm{g} / \mathrm{mL}$ or greater) was $97.9 \%$, with a GMC of $4.86 \mu \mathrm{g} / \mathrm{mL}$. Anti-PRP concentrations waned between seven and 18 months of age to a GMC of $0.55 \mu \mathrm{g} / \mathrm{mL}$, but $85.2 \%$ of subjects remained seroprotected. The booster at 18 months of age elicited an anamnestic response, achieving a GMC of $32.3 \mu \mathrm{g} / \mathrm{mL}$, with $100 \%$ of infants having an anti-PRP antibody of $0.15 \mu \mathrm{g} / \mathrm{mL}$ 


\section{TABLE 5}

Antibody responses to polyribosylribitol phosphate polysaccharide conjugated to tetanus toxoid (PRP-T) after primary series and before and after booster immunization of infants with fully liquid DTaP-IPV-Hib vaccine

\begin{tabular}{ccccc}
\hline & & \multicolumn{3}{c}{ Antibody responses at indicated age } \\
\cline { 3 - 5 } Antigen & Result & $\begin{array}{c}\mathbf{7} \text { months } \\
(\mathbf{n = 3 2 4})\end{array}$ & $\begin{array}{c}\mathbf{1 8} \text { months } \\
(\mathbf{n = 3 0 1 )}\end{array}$ & $\begin{array}{c}\mathbf{1 9} \text { months } \\
(\mathbf{n = 3 0 1 )}\end{array}$ \\
\hline $\mathrm{PRP}-\mathrm{T}$, & $\mathrm{GMC}$ & 4.86 & 0.55 & 32.3 \\
$\mu \mathrm{g} / \mathrm{mL}$ & $95 \% \mathrm{Cl}$ & $4.21-5.62$ & $0.48-0.64$ & $28.4-36.8$ \\
& $\% \geq 0.15$ & 97.9 & 85.2 & 100 \\
& $\% \geq 1.0$ & 88.9 & 24.8 & 99.0 \\
\hline
\end{tabular}

DTaP-IPV-Hib Diphtheria, tetanus and acellular pertussis, inactivated polio vaccine and Haemophilus influenzae type b; GMC Geometric mean antibody concentration

or greater and $99 \%$ of infants having an anti-PRP antibody of $1.0 \mu \mathrm{g} / \mathrm{mL}$ or greater.

Comparison of antibody responses to fully liquid DTaP-IPV-Hib and reconstituted DTaP-IPV//Hib

Antibody responses to the fully liquid and reconstituted acellular pertussis combination vaccines are summarized in Table 6. As is apparent from Table 6, the responses to primary immunization at two, four, and six months of age and to a booster at 18 months of age are comparable against all antigens in the combination products. No clinically significant differences in GMCs or seroresponse rates were observed (data not shown). Although GMTs to the three serotypes of poliovirus were lower after the Vero-cell IPV contained in the fully liquid vaccine than after the MRC-5 cell IPV contained in the reconstituted vaccine, the titres after both primary and booster immunization were so high that the differences were unlikely to have any clinical significance. All subjects achieved protective titres (1:8 or greater) after both primary and booster immunizations.

\section{DISCUSSION}

The present study was performed to evaluate the reactogenicity and immunogenicity of three production lots of the fully liquid DTaP-IPV-Hib combination vaccine. Because no significant lotto-lot differences were observed, with one exception discussed below, pooled data for all three lots are presented. The vaccine was generally well tolerated in both the primary series and as a booster dose at 18 months of age. Most adverse events occurred within $24 \mathrm{~h}$ of vaccination and resolved rapidly. Tenderness was the most frequent injection site reaction, affecting approximately $15 \%$ to $23 \%$ of the subjects during the primary series, but severe tenderness was reported for less than $2.5 \%$ of doses and lasted less than $24 \mathrm{~h}$. Rates of tenderness were slightly greater after the booster dose $(35.5 \%)$ as previously noted for other DTaP vaccines, but the rate of severe tenderness remained below $2 \%$. The most frequent systemic reactions after the primary series were fussiness (48\% to $57 \%$ ), crying (31\% to $45 \%)$ and fever $(15.1 \%$ to $23.5 \%$ ), but there were no cases of fever of $40^{\circ} \mathrm{C}$ or higher within $72 \mathrm{~h}$ of vaccination during the primary series. Except for fever, systemic reactions were less frequent after the booster at 18 months of age.

Immunogenicity data were also similar for all three lots of fully liquid DTaP-IPV-Hib, there being only one statistically significant lot-to-lot difference - a higher FHA GMC with one lot than the others. GMCs to PT, PRN and FIM were comparable among all three lots. Immune responses to all
TABLE 6

Antibody responses to immunization with fully liquid (DTaP-IPV-Hib) or reconstituted (DTaP-IPVI/Hib) acellular pertussis combination vaccines in infants at two, four, six and 18 months of age

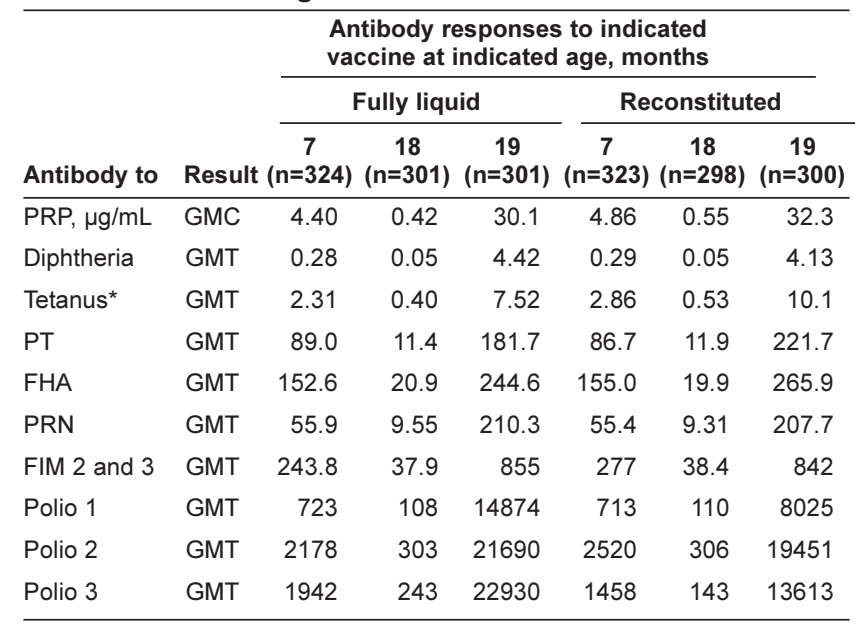

*Tetanus antitoxin values standardized for change in ELISA assay between seven and 18 months by multiplying seven-month values by 2.62. DTaP-IPV-Hib Diphtheria, tetanus and acellular pertussis, inactivated polio vaccine and Haemophilus influenzae type b; FHA Filamentous hemagglutinin; FIM Fimbriae; GMC Geometric mean antibody concentration; GMT Geometric mean antibody titre; PRN Pertactin; PRP Polyribosylribitol phosphate; PT Pertussis toxoid

vaccine components for all three lots were satisfactory in that protective responses against diphtheria, tetanus, poliovirus and Hib were obtained in $98 \%$ to $100 \%$ of subjects after the primary series and the booster.

The safety (Tables 1 and 2) and immunogenicity (Table 6) results in the fully liquid vaccine were comparable with those seen in the reconstituted DTaP-IPV//Hib. Although there are no generally accepted serological markers of protection against pertussis, the high antibody responses observed against the five acellular pertussis components are similar in magnitude to those reported previously with reconstituted DTaP-IPV//Hib studied in the same general population with the same methodologies (27). This five-component acellular pertussis vaccine has been shown to have an $85 \%$ efficacy in preventing severe pertussis disease in Swedish field trials $(20,21)$. Similar seroprotection and vaccine response rates to the component antigens were observed in two more recent studies $(41,42)$ of the vaccine conducted in Mexico and Taiwan using the same administration schedule.

Studies with most acellular pertussis combination vaccines have shown statistically significant reductions in the response to the Hib component when both are combined as a single injection compared with responses to the acellular pertussis combination vaccine and $\mathrm{Hib}$ conjugate vaccine administered concurrently as separate injections (34-37). In the previous report (27), Hib responses to reconstituted DTaP-IPV//Hib (GMC $=4.40 \mu \mathrm{g} / \mathrm{mL}, 95 \%$ CI 3.78 to 5.13 ) compared favourably with concurrent, separate injections of DTaP-IPV and Hib (GMC $=3.83 \mu \mathrm{g} / \mathrm{mL}, 95 \%$ CI 3.05 to 6.53 ), showing that there was no interference with this response due to reconstitution with DTaP-IPV. The similar Hib response to the fully-liquid formulation in the present report $(\mathrm{GMC}=4.86 \mu \mathrm{g} / \mathrm{mL}, 95 \% \mathrm{CI} 4.21$ to 5.62 ), with $98 \%$ of children achieving levels of $0.15 \mu \mathrm{g} / \mathrm{mL}$ or greater and $89 \%$ achieving levels of $1.0 \mu \mathrm{g} / \mathrm{mL}$ or greater after the third primary dose, indicates that interference is also unlikely with 
this formulation. In addition, the booster dose elicited a strong anamnestic response, with an anti-PRP GMT of $32.3 \mu \mathrm{g} / \mathrm{mL}$ one month after booster vaccination; all children had seroprotective anti-PRP titres $(0.15 \mu \mathrm{g} / \mathrm{mL}$ or greater $)$ and $99 \%$ reached concentrations associated with prolonged protection $(1.0 \mu \mathrm{g} / \mathrm{mL}$ or greater).

Since its introduction in 1998, the reconstituted DTaP. IPV//Hib has been used routinely for immunization of infants in Canada. The incidence of reported cases of pertussis and the hospitalization rate for pertussis has shown a statistically significant decrease in age cohorts that have received at least two doses of acellular pertussis vaccine $(28,43-45)$. In addition, since the introduction of reconstituted DTaP-IPV//Hib vaccine, there has been no change in the number of cases of invasive Hib disease detected by active surveillance at 12 tertiary care pediatric centres in Canada $(32,46)$.

The similarities in the compositions of the DTaP-IPV-Hib and the DTaP-IPV//Hib vaccines and in their abilities to induce comparable immune responses suggest that both will have similar clinical efficacies. The extensive experience gained with the DTaP-IPV//Hib vaccine in Canada since 1998 has shown it to be fully effective against diphtheria, tetanus, pertussis, polio and Hib. The present report demonstrates that the DTaP-IPV-Hib vaccine elicits serological immune responses to all components equivalent to those of the DTaP-IPV//Hib vaccine. We anticipate, therefore, that it will provide equal efficacy while the fully liquid formulation will increase the ease of administration. Further clinical studies of this vaccine are currently underway in Europe.

ACKNOWLEDGEMENTS: The present study originated from sanofi pasteur Ltd, Canada. The authors gratefully acknowledge the assistance of David Greenberg, Fernando Noriega, Lisa DeTora and Walter Woods (sanofi pasteur, USA), Eric Desauziers, Keith Veitch and Clement Weinberger (sanofi pasteur, France), and Maher Issa and Peter Lashley (sanofi pasteur, Canada) in reviewing the manuscript.

The study was presented, in part, at the following meetings:

1. Thipphawong J, Barreto L, Mills E, et al. A fully-liquid, acellular pertussis vaccine combined with IPV and Hib vaccines (DTaP-IPV-Hib) is safe and immunogenic without significant interactions (Workshop W3E). International Conference on Acute Respiratory Infections. Canberra, July 7 to 10, 1997.

2. Mills E, Russell M, Cunning L et al. A fully liquid acellular pertussis vaccine combined with IPV and Hib vaccines (DTaP-IPV-Hib) is safe and immunogenic without significant interactions. Interscience Conference on Antimicrobial Agents and Chemotherapy. Toronto, Sept 28 to Oct 1,1997.

3. Mills E, Russell M, Cunning L, et al. Comparative immunogenicity of an acellular pertussis-inactivated polio (DTaP-IPV) vaccine used to reconstitute lyophilized $H$ influenzae $b$ (PRP-T) or licensed DTwP-IPV-PRP-T vaccine in infants. Society for Pediatric Research, Washington DC, May 2 to 6, 1997.

4. Mills E, Xie F, Gold R, Harrison DL. Immune responses to inactivated polio vaccines in combination with other vaccines. Infectious Disease Society of America 39th Annual Meeting, San Francisco, Oct 25 to 28, 2001.

\section{REFERENCES}

1. Halperin SA, Barreto L, Eastwood BJ, Law B, Roberts EA. Safety and immunogenicity of a five-component acellular pertussis vaccine with varying antigen quantities. Arch Pediatr Adolesc Med 1994;148:1220-4.

2. Halperin SA, Mills E, Barreto L, Pim C, Eastwood BJ. Acellular pertussis vaccine as a booster dose for seventeen- to nineteen-month-old children immunized with either whole cell or acellular pertussis vaccine at two, four and six months of age. Pediatr Infect Dis J 1995;14;792-7.

3. Halperin SA, Eastwood B, Barreto L, et al. Safety and immunogenicity of two acellular pertussis vaccines with different pertussis toxoid and filamentous hemagglutinin content in infants 2-6 months old. Scand J Infect Dis 1995;27:279-87.

4. Halperin SA, Eastwood BJ, Barreto L, et al. Adverse reactions and antibody response to four doses of acellular or whole cell pertussis vaccine combined with diphtheria and tetanus toxoids in the first 19 months of life. Vaccine 1996;14:767-72.

5. Halperin SA, Barreto L, Eastwood BJ, et al. Safety and immunogenicity of an acellular pertussis diphtheria tetanus vaccine given as a single injection with Haemophilus influenzae b conjugate vaccine. Vaccine 1997;15:295-300.

6. Halperin SA, Davies HD, Barreto L, et al. Safety and immunogenicity of two inactivated poliovirus vaccines in combination with an acellular pertussis vaccine and diphtheria and tetanus toxoids in seventeen- to nineteen-month-old infants. J Pediatr 1997;130:525-31.

7. Anderson EL, Belshe RB, Bartram J. Differences in reactogenicity and antigenicity of acellular and standard pertussis vaccine combined with diphtheria and tetanus in infants. J Infect Dis $1988 ; 157: 731-7$.

8. Blumberg DA, Mink CM, Cherry JD, et al. Comparison of acellular and whole-cell pertussis-component diphtheria-tetanus-pertussis vaccines in infants. The APDT Vaccine Study Group. J Pediatr 1991;119:194-204.

9. Decker MD, Edwards KM, Steinhoff MC, et al. Comparison of 13 acellular pertussis vaccines: Adverse reactions. Pediatrics 1995;96:557-66.

10. Edwards KM, Meade BD, Decker MD, et al. Comparison of 13 acellular pertussis vaccines: Overview and serologic response. Pediatrics 1995;96:548-57.

11. Rosenthal S, Chen R, Hadler S. The safety of acellular pertussis vs whole-cell pertussis vaccine. A postmarketing assessment. Arch Pediatr Adolesc Med 1996;150:457-60.

12. Black SB, Shinefield HR, Bergen R, et al. Safety and immunogenicity of Chiron/Biocine recombinant acellular pertussis-diphtheria-tetanus vaccine in infants and toddlers. Pediatr Infect Dis J 1997;16:53-8.

13. Miller E, Ashworth LA, Redhead K, Thornton C, Waight PA, Coleman T. Effect of schedule on reactogenicity and antibody persistence of acellular and whole-cell pertussis vaccines: Value of laboratory tests as predictors of clinical performance. Vaccine 1997; 15:51-60.

14. Schmitt HJ, Schuind A, Knuf M, et al. Clinical experience of a tricomponent acellular pertussis vaccine combined with diphtheria and tetanus toxoids for primary vaccination in 22,505 infants. J Pediatr 1996;129:695-701.

15. Schmitt HJ, Beutel K, Schuind A, et al. Reactogenicity and immunogenicity of a booster dose of a combined diphtheria, tetanus, and tricomponent acellular pertussis vaccine at fourteen to twenty-eight months of age. J Pediatr 1997;130:616-23.

16. Ad Hoc Group for the Study of Pertussis Vaccines. Placebo-controlled trial of two acellular pertussis vaccines in Sweden - protective efficacy and adverse events. Lancet 1981;1:955-60. (Erratum in 1988;1:1238).

17. Storsaeter J, Blackwelder WC, Hollander HO. Pertussis antibodies, protection and vaccine efficacy after household exposure. Am J Dis Child 1992;146:167-72.

18. Trollfors B, Tarranger J, Lagergård T, et al. A placebo-controlled trial of a pertussis-toxoid vaccine. N Engl J Med 1995;333:1045-50.

19. Greco D, Salmaso S, Mastrantonio T, et al. A controlled trial of two acellular vaccines and one whole-cell vaccine against pertussis. Progetto Pertosse Working Group. N Engl J Med 1996;334:341-8.

20. Gustafsson L, Hallander HO, Olin P, Reizenstein E, Storsaeter J. A controlled trial of a two-component acellular, a five-component acellular, and a whole-cell pertussis vaccine. N Engl J Med 1996;334:349-55. (Erratum in 2;334:1207).

21. Olin P, Rasmussen F, Gustafsson L, Hallander HO, Heijbel H. Randomised controlled trial of two-component, three-component, and five-component acellular pertussis vaccines compared with whole-cell pertussis vaccine. Ad Hoc Group for the Study of Pertussis Vaccines. Lancet 1997;350:1569-77. (Erratum in 1998;351:454). 
22. Schmitt HJ, von König CH, Neiss A, et al. Efficacy of acellular pertussis vaccine in early childhood after household exposure. JAMA 1996;275:37-41.

23. Taranger J, Trollfors $B$, Lagergård $T$, et al. Unchanged efficacy of a pertussis toxoid vaccine throughout the two years after the third vaccination of infants. Pediatr Infect Dis J 1997;16:180-4.

24. Trollfors B, Taranger J, Lagergård T, et al. Efficacy of a monocomponent pertussis toxoid vaccine after household exposure to pertussis. J Pediatr 1997;130:532-6.

25. Simondon F, Preziosi MP, Yam A, et al. A randomized double-blind trial comparing a two-component acellular to a whole-cell pertussis vaccine in Senegal. Vaccine 1997;15:1606-12.

26. National Advisory Committee on Immunization. Statement on pertussis vaccine. Can Commun Dis Rep 1997;23:1-16.

27. Mills E, Gold R, Thipphawong J, et al. Safety and immunogenicity of a combined five-component pertussis-diphtheria-tetanusinactivated poliomyelitis-Haemophilus $\mathrm{b}$ conjugate vaccine administered to infants and two, four and six months of age. Vaccine 1998;16:576-85

28. Halperin SA, McDonald J, Samson L, et al. Simultaneous administration of meningococcal $\mathrm{C}$ conjugate vaccine and diphtheria-tetanus-acellular pertussis-inactivated poliovirusHaemophilus influenzae type $\mathrm{b}$ conjugate vaccine in children: A randomized controlled trial. Clin Invest Med 2002;25:243-51.

29. Scheifele DW, Halperin SA, Smith B, Ochnio J, Meloff K, Duarte-Monteiro D. Assessment of the compatibility of co-administered 7-valent pneumococcal conjugate, DTaP-IPV/PRP-T $\mathrm{Hib}$ and hepatitis $\mathrm{B}$ vaccines in infants $2-7$ months of age. Vaccine 2006;24:2057-64

30. Galanis E, King AS, Varughese P, Halperin SA; IMPACT investigators. Changing epidemiology and emerging risk groups for pertussis. CMAJ 2006;174:451-2.

31. Le Saux N, Barrowman NJ, Moore DL, Whiting S, Scheifele D, Halperin S; Canadian Paediatric Society/ Health Canada Immunization Monitoring Program-Active (IMPACT). Decrease in hospital admissions for febrile seizures and reports of hypotonic-hyporesponsive episodes presenting to hospital emergency departments since switching to acellular pertussis vaccine in Canada: A report from IMPACT. Pediatrics 2003;112:e348.

32. Scheifele D, Halperin S, Law B, et al; Canadian Paediatric Society/ Health Canada Immunization Monitoring Program, Active. Invasive Haemophilus influenzae type $\mathrm{b}$ infections in vaccinated and unvaccinated children in Canada, 2001-2003. CMAJ 2005;172:53-6.

33. Donaldson L, Mullaly S, Smith J. New vaccinations for the childhood immunisation programme. < http://www.dh.gov.uk/en/ Publicationsandstatistics/Lettersandcirculars/Professionalletters/ Chiefpharmaceuticalofficerletters/DH_4087350> (Lett)

34. Schmitt HJ, Zepp F, Muschenborn S, et al. Immunogenicity and reactogenicity of a Haemophilus influenzae type b tetanus conjugate vaccine when administered separately or mixed with concomitant diphtheria-tetanus-toxoid and acellular pertussis vaccine for primary and for booster immunizations. Eur J Pediatr 1998;157:208-14.

35. Pichichero ME, Latiolais T, Bernstein DI, et al. Vaccine antigen interactions after a combination diphtheria-tetanus toxoid-acellular pertussis/purified capsular polysaccharide of Haemophilus influenzae type b-tetanus toxoid vaccine in two-, four- and six-month-old infants. Pediatr Infect Dis J 1997;16:863-70.

36. Eskola J, Olander RM, Hovi T, Litmanen L, Peltola S, Käyhty H. Randomised trial of the effect of co-administration with acellular pertussis DTP vaccine on immunogenicity of Haemophilus influenzae type b conjugate vaccine. Lancet 1996;348:1688-92.

37. Amir J, Melamed R, Bader J, et al. Immunogenicity and safety of a liquid combination of DTP-PRP-T [corrected] vs lyophilized PRP-T reconstituted with DTP. Vaccine 1997;15:149-54. (Erratum in 1997;15:1813).

38. National Advisory Committee on Immunization. Canadian Immunization Guide, 4th edn. Ontario: Health Canada, 1993:87-9.

39. Manclark CR, Meade BD, Burstyn, DG. Serological response to Bordetella pertussis. In: Eds Rose, NR, Friedman H, Fahey JL, eds. Manual of Clinical Laboratory Immunology, 3rd edn. Washington DC: American Society of Microbiology,1986:388-94.

40. Ipp MM, Gold R, Goldbach M, et al. Adverse reactions to diphtheria, tetanus, pertussis-polio vaccination at 18 months of age: Effect of injection site and needle length. Pediatrics 1989;83:679-82.

41. Castañeda JL, Gonzalez N, Lavigne P, Ortiz E. Immunogenicity and safety of a fully liquid DTaP-IPV-Hib vaccine with full primary IPV or sequential IPV-OPV in Mexican infants. Int J Infect Dis 2004;8:S71. (Abst)

42. Lin TY, Wang YH, Chang LY, et al. A fully liquid diphtheria-tetanus-five component acellular pertussis-inactivated poliomyelitis-Haemophilus influenzae type $b$ conjugate vaccine: Immunogenicity and safety of primary vaccination in Taiwanese infants. Int J Infect Dis 2007;11:129-36.

43. National consensus conference on pertussis, Toronto, May 25-28, 2002. Can Commun Dis Rep 2003;29(Suppl 3):1-36.

44. Bettinger JA, Halperin SA, De Serres G, Scheifele DW, Tam T. The effect of changing from whole-cell to acellular pertussis vaccine on the epidemiology of hospitalized children with pertussis in Canada. Pediatr Infect Dis J 2007;26:31-5.

45. Halperin SA, De Serres G. Has the change from acellular to pertussis vaccine improved or worsened pertussis control? CMA] 2006; 175:1227.

46. Gold R, Scheifele D, Barreto L, et al. Safety and immunogenicity of Haemophilus influenzae vaccine (tetanus toxoid conjugate) administered concurrently or combined with diphtheria and tetanus toxoids, pertussis vaccine and inactivated poliomyelitis vaccine to healthy infants at two, four and six months of age. Pediatr Infect Dis J 1994;13:348-55. 


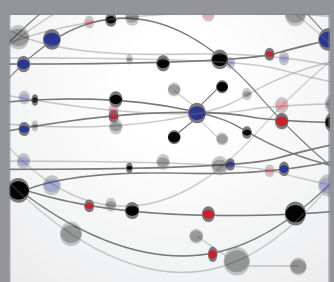

The Scientific World Journal
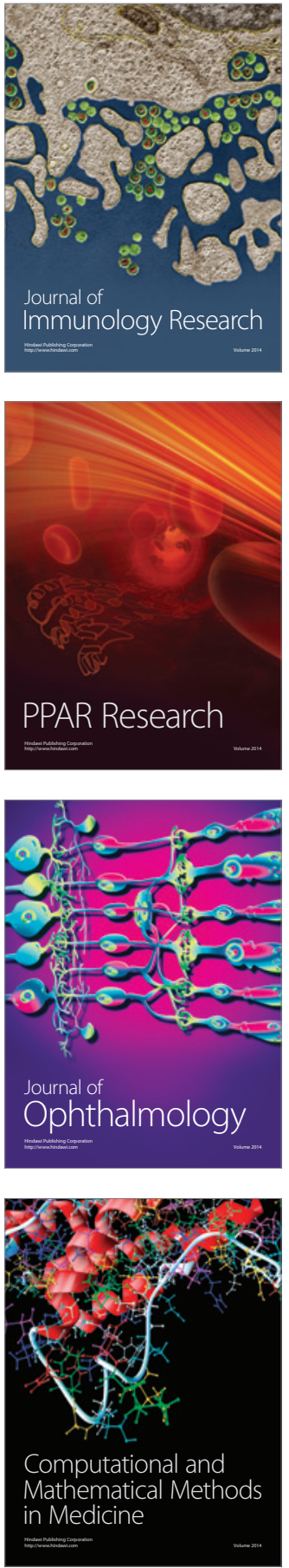

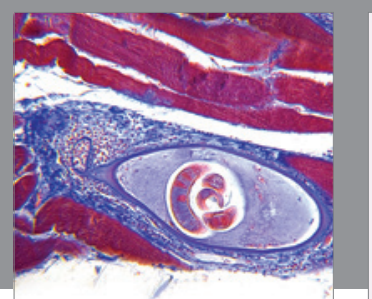

Gastroenterology Research and Practice

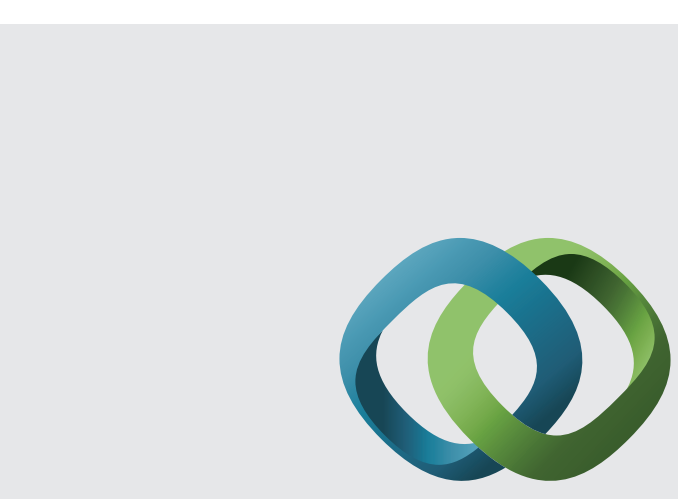

\section{Hindawi}

Submit your manuscripts at

http://www.hindawi.com
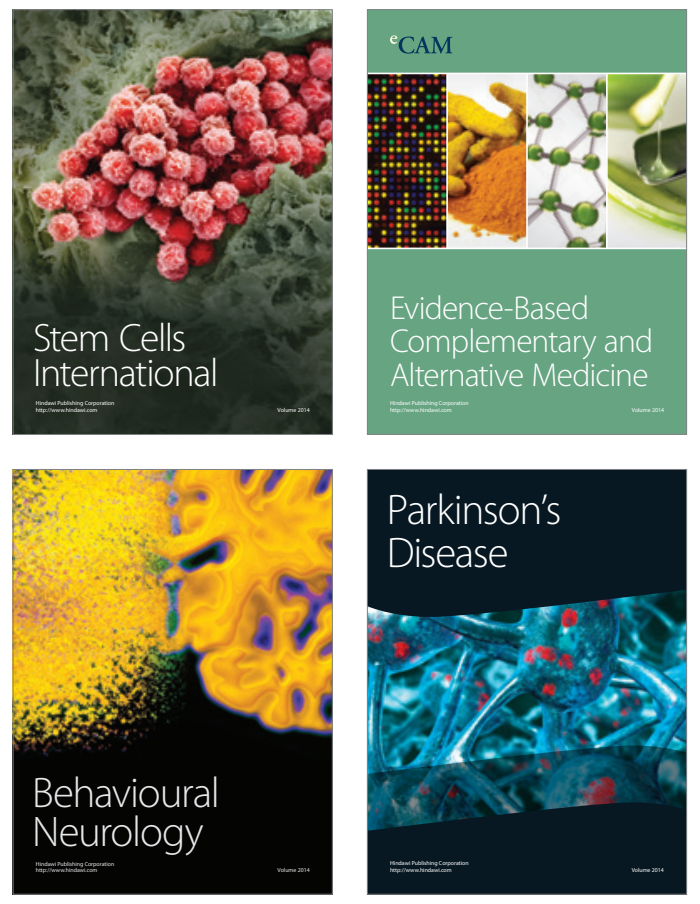
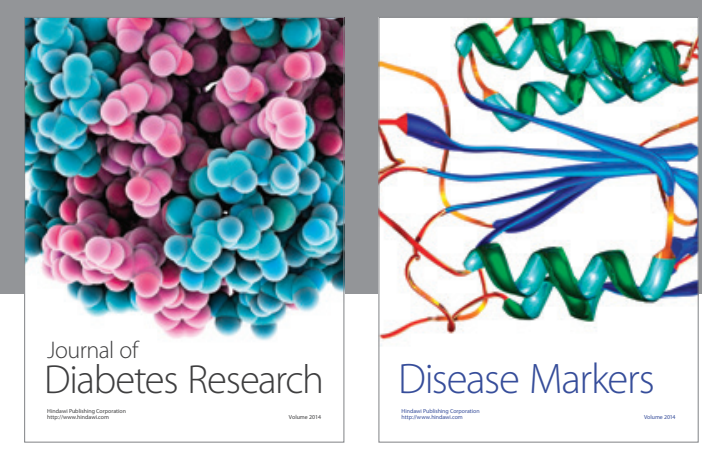

Disease Markers
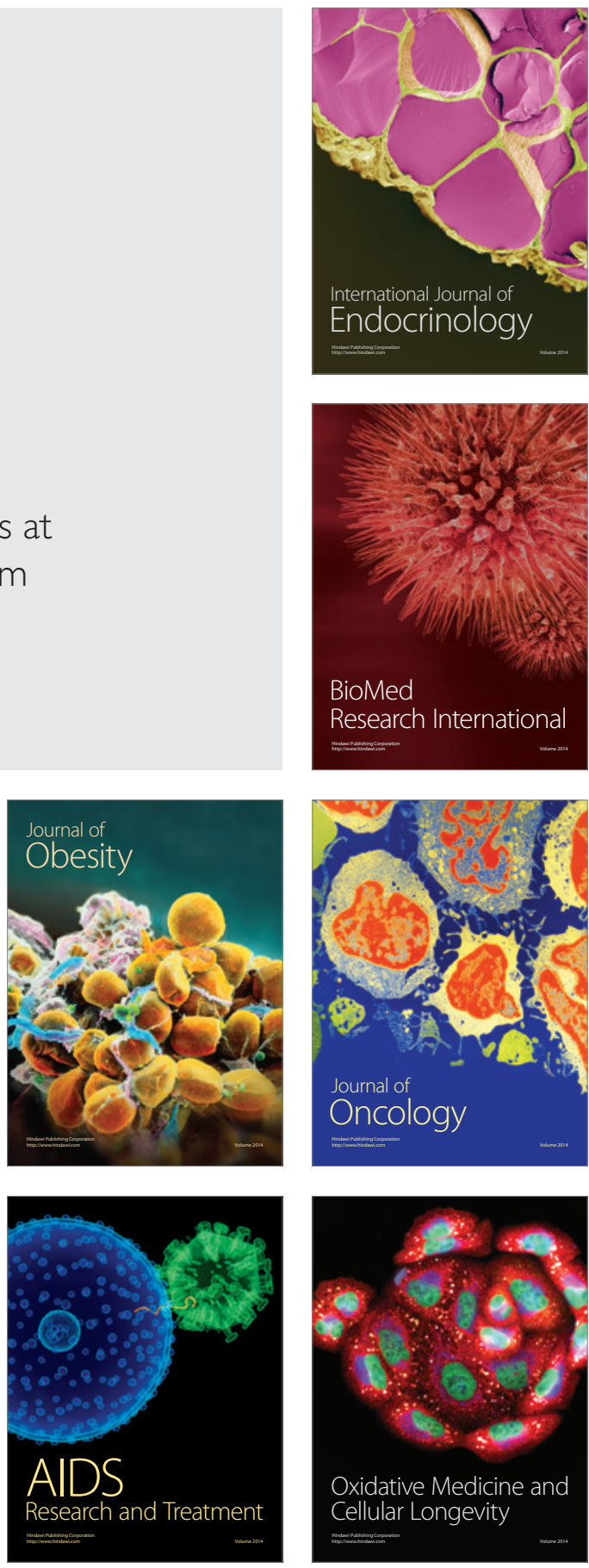